\title{
Ni cantamos ni perdemos la esperanza
}

"No es tiempo todavía de cantar victoria por la vigencia de los derechos humanos, pero tampoco es tiempo aún para la desesperanza". Esas fueron las palabras finales del último análisis que, sobre la situación del país, hizo el fundador del recientemente desaparecido Socorro Jurídico Cristiano y del Instituto de Derechos Humanos de la UCA (IDHUCA). A más de cinco años desde su asesinato, ejecutado por efectivos de la Fuerza Armada, junto a sus cinco compañeros y dos colaboradoras, las palabras del padre Segundo Montes continúan golpeando nuestros sentidos por su enorme validez, pues constituyen un diagnóstico acertado de lo que está sucediendo actualmente en El Salvador y nos sirven para desarrollar nuestras apreciaciones, sobre todo de cara a las perspectivas futuras y al considerar que -dentro de unos meses - finalizará la verificación que todavía mantiene en nuestro país la comunidad internacional.

Y surge la primera interrogante: ¿por qué todavía no podemos ni debemos cantar victoria? $\mathrm{La}$ respuesta: porque el respeto a los derechos humanos no se alcanza, automática y simplemente, con el fin de la beligerancia o la realización formal de elecciones. Estos dos elementos, presentados como los grandes logros del proceso actual, sin despreciarlos, son muy precarios para considerarlos bases sólidas que aseguren la irreversibilidad del mismo cuando - en lo cotidianovivimos un conflicto social en el cual las condiciones de injusticia así como la situación de inseguridad y violencia en que permanece la mayoría de las salvadoreñas y de los salvadoreños, siguen impidiendo su participación activa y consciente en el uso y funcionamiento de los mecanismos internos para garantizar la vigencia real de sus derechos civiles, políticos, económicos, sociales y culturales.

Podríamos empezar a entonar cantos de triunfo si, en este momento, tres de las instituciones creadas o reformadas por los acuerdos de paz estuvieran funcionando a un nivel suficientemente aceptable para generar la necesaria credibilidad entre la población, a fin de que ésta empiece a superar miedos y desconfianzas que aún privan en ella y que -tal como se han desarrollado los acontecimientos- siguen siendo los dos grandes obstáculos para su participación en la instauración y consolidación de un verdadero Estado de derecho en El Salvador. Sin embargo, a la fecha, tanto la Policía Nacional Civil y la Corte Suprema de Justicia, así como la Procuraduría para la Defensa de los Derechos Humanos no se han convertido en los pilares sólidos de una nueva sociedad, donde la dignidad de todas y de todos sus integrantes se encuentre en el lugar más privilegiado.

Al hablar de la nueva policía debemos señalar que desde el inicio de su funcionamiento, algunos organismos de la sociedad civil que trabajan en la promoción y defensa de los derechos humanos empezaron a recibir denuncias puntuales contra algunos de sus agentes, pues éstos eran responsables de determinadas violaciones, situación que también ha sido conocida por ONUSAL. Esta afirmó en el onceavo informe del director de su 
división de derechos humanos, dirigido al secretario general del organismo internacional, que la mayoría de los actos imputados a la Policía Nacional Civil "tienen su origen en el desconocimiento o la falta de aplicación de las normas jurídicas que rigen su actividad". En palabras más sencillas, ONUSAL sostiene que estos hechos ocurrieron porque los nuevos policías no conocían bien la ley o no la supieron aplicar, lo que cuestiona la formación que se les está brindando.

Pero la explicación de este inquietante fenómeno, que no parece disminuir, no debe limitarse a esas deficiencias, pues entre marzo y junio, ONUSAL comprobó la participación de agentes de la Policía Nacional Civil en veintidós violaciones que incluyen malos tratos, tortura, amenazas y una ejecución arbitraria. Esto es aún más preocupante, pues no es necesario que una persona -y más un miembro de la nueva policía- conozca en todos sus detalles la ley para saber que maltratar, torturar, amenazar y ejecutar a un ser humano son acciones que la contrarían.

La explicación de fondo es otra y también la señala ONUSAL cuando dice que "entre las causas que pueden concurrir a la explicación de las violaciones a los derechos humanos cometidas por miembros de la Policía Nacional Civil puede estar la incorporación de la Unidad Ejecutiva Antinarcotráfico (UEA) y la Comisión Investigadora de Hechos Delictivos (CIHD) a la Policía Nacional Civil, sin modificación o depuración alguna y sin haber seguido los cursos ordinarios en la Academia Nacional de Seguridad Pública". Y en eso hay mucho de cierto, pues dichos elementos se formaron en la escuela de la represión, los "escuadrones", la corrupción y el encubrimiento que prevalecieron en la Policía Nacional. Con lo anterior, la Policía Nacional Civil ha empezado a caer peligrosamente en los vicios de los antiguos cuerpos de seguridad.

Pero en su siguiente análisis sobre la Policía Nacional Civil —el cual aparece en el doceavo informe sobre la situación de los derechos humanos-, ONUSAL afirma que ahora contamos "con un nuevo cuerpo de seguridad basado en una nueva doctrina" no obstante, en la práctica, existan factores que impiden un mejor desempeño de ésta.
Entre ellos señala "las deficiencias de ciertas instituciones, como el aparato judicial," así como "la resistencia de factores minoritarios". En ese marco, se sitúan las 87 denuncias a la Misión de violaciones de los derechos humanos admitidas por ONUSAL entre julio y septiembre, cuya responsabilidad se presume recae en miembros del cuerpo policial. De éstas, en veintiséis se confirmó que hubo violación; en veintiún casos se estableció que no hubo tal violación; en siete casos resultó imposible realizar la verificación; y, finalmente, falta concluir la investigación de treinta y tres casos.

En este último informe, ONUSAL considera que las violaciones denunciadas responden a dos situaciones. La primera, "el desconocimiento o errónea interpretación de la normativa vigente por parte de los policías, como en el caso de las detenciones arbitrarias". Esto se debe a "la inexistencia de un marco jurídico uniforme, claro y concreto, que imponga límites precisos a la actuación policial", a "la insuficiente formación básica jurídica que reciben los efectivos de la Policía Nacional Civil en la Academia de Seguridad Pública", a una asesoría jurídica "deficiente e incluso contraria a la doctrina del nuevo cuerpo policial, lo que ha contribuido a la realización de procedimientos irregulares" y a "deficiencias de mando en la Policía Nacional Civil" que conducen a la carencia de "orientaciones claras, definidas y uniformes, hecho que propicia que los policías deban llenar a su propia iniciativa, el vacío dejado por órdenes precisas".

Según ONUSAL, la segunda situación que propicia las violaciones es más compleja y se encuentra conformada por "la utilización excesiva de la fuerza por parte de los efectivos en sus operativos", donde el recurso a usar "las armas de fuego ante cualquier circunstancia sigue siendo una constante"; por la existencia de "preocupantes gérmenes de prepotencia"; por los alegatos de "desconocimiento" de las violaciones o por el entorpecimiento de su investigación, por acción u omisión, por parte de los responsables jerárquicos de la Policía Nacional Civil y, finalmente, por la falta de "la necesaria rigidez que en esta etapa fundacional de la Policía Nacional Civil deben 
seguir los procedimientos disciplinarios internos". Sin dudarlo, hasta aquí estamos de acuerdo con los elementos que señala ONUSAL como factores que inciden en las violaciones de los derechos humanos atribuidas a los miembros de la Policía Nacional Civil, pero no compartimos las siguientes dos situaciones.

En primer lugar y no obstante señalarlo antes en el onceavo informe, ahora los observadores internacionales ya no mencionen una de las causas más importantes para que estos hechos se sigan produciendo en la actualidad y puedan aumentar en el futuro, cuando ya no esté la Misión en el país: las actividades de la Comisión Investigadora de Hechos Delictivos y de la Unidad Ejecutiva Antinarcotráfico - ahora División de Investigación Criminal y División Antinarcóticos-, incorporadas a la Policía Nacional Civil sin cumplir con los requisitos acordados. Esta omisión es más grave aún, sobre todo cuando nos enfrentamos a la posibilidad cierta de que al nuevo cuerpo de seguridad se incorporen los efectivos del batallón antidelincuencial de la Policía Nacional que se encuentra en su etapa final de extinción, aunque las unidades mencionadas sobrevivan con otros nombres.

El otro aspecto del análisis de ONUSAL sobre la Policía Nacional Civil con el cual no estamos de acuerdo, es la peligrosa referencia que se hace a la actitud de la población ante sus agentes, para justificar o explicar las violaciones en que éstos incurren. Es muy grave y preocupante que -en el párrafo 44 del último informe de la división de derechos humanos de ONUSAL- se afirme que algunos actos contra los derechos humanos cometidos por miembros de la Policía Nacional Civil responden a que éstos se enfrentan "con cierta inseguridad" a una población que les "reclama mayor efectividad en la persecución del delito y la seguridad ciudadana, a la vez que está dispuesta a exigirle un mejor trato, respetuoso de los derechos humanos". ¿Qué hacer entonces? ¿Debemos desalentar la incipiente participación activa de la población común y corriente en la fiscalización de los servidores públicos y en el requerimiento del respeto a sus derechos y libertades fundamentales? ¿Debemos alentar a los nuevos policías para que profundicen el uso arbitrario de su autoridad como forma para enfrentar esa "actitud ciudadana"? La respuesta es clara, hay que motivar a la población para que aumente la exigencia de respeto a sus derechos y libertades por parte de un cuerpo policial que debe conocer - con urgencia y cada vez más- sus atribuciones, que debe hacer uso de ellas sin abusar y que, sobre todo, debe considerarse como parte de la población y al servicio de ella. Esta es la respuesta que debió haber dado ONUSAL.

De todo lo mencionado, debe retomarse el final del análisis sobre la nueva policía. Ahí se afirma que muchas de las irregularidades detectadas en el proceder de los agentes, sobre todo en materia de respeto a la dignidad de las personas, responde a la falta de funcionamiento eficaz de los mecanismos de control internos y externos, que es a lo que ONUSAL se refiere cuando habla de que no se ha alcanzado "la necesaria rigidez que en esta etapa fundacional de la Policía Nacional Civil deben seguir los procedimientos disciplinarios internos". Nombrado en los últimos días de septiembre, el titular de la inspectoría general de la Policía Nacional Civil aún se encuentra en una etapa de arranque que, de prolongarse más, puede

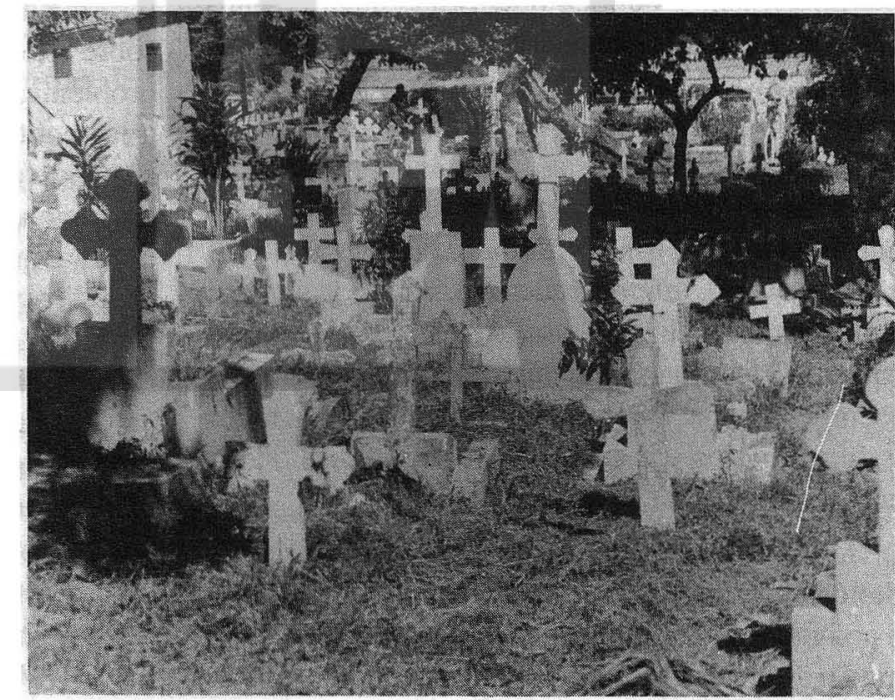


llevar a que esta instancia no cumpla cabalmente con la función establecida en el artículo 8 de la Ley Orgánica de la Policía Nacional Civil: "vigilar y controlar las actuaciones de los servicios operativos y de gestión del cuerpo, así como lo referente a los derechos humanos". Como sea, a casi tres meses de su nombramiento, el inspector general no ha dado señales visibles y ejemplarizantes de su existencia; lo mismo sucede con las otras instancias de control interno, sobre todo la unidad de investigación disciplinaria. Sobre los problemas con los mecanismos externos para vigilar su funcionamiento, nos referimos en seguida.

Primero abordaremos la actuación de la Procuraduría para la Defensa de los Derechos Humanos, pues en el citado artículo 8 de la Ley Orgánica de la Policía Nacional Civil también se establece que el inspector general "rendirá al Procurador para la Defensa de los Derechos Humanos, informe ordinario cada seis meses y de forma extraordinaria cada vez que se le solicite por dicho funcionario". Con eso queda establecida una relación directa de control, vigilancia y supervisión sobre la Policía Nacional Civil por parte del titular de la Procuraduría para la Defensa de los Derechos Humanos, que se agrega a las derivadas de las amplias atribuciones legales que éste tiene y cuya misión puede resumirse en la defensa de los particulares frente a las acciones de la administración pública que violan sus derechos y libertades fundamentales, mediante la investigación y el señalamiento de los errores en forma abierta o privada. Así, a la Procuraduría para la Defensa de los Derechos Humanos no sólo le corresponde incidir con su actuación en el buen desempeño de los miembros de la Policía Nacional Civil, a partir de ese vínculo especial determinado en el mencionado artículo que crea su inspectoría general, sino que también le compete desempeñar una labor mayor en relación a todos los funcionarios y a su conducta respetuosa de los derechos humanos.

Desde la perspectiva de este comentario, la falta de funcionamiento eficaz de las instituciones, la actividad de la Procuraduría puede ser considerada desde la forma cómo la institución estatal encargada de la promoción y protección de los derechos humanos ha observado el funcionamiento del nuevo cuerpo de seguridad. Y es imposible perderse ya que, también en esta temática tan importante para el proceso salvadoreño, la actuación de la Procuraduría no ha estado a la altura de las necesidades. Es difícil aceptar que cuando la realidad obligaba a ONUSAL —a pesar de sus típicas expresiones diplomáticas- a señalar las deficiencias antes mencionadas de la Policía Nacional Civil, la Procuraduría para la Defensa de los Derechos Humanos se limitase a describir en su quinto informe (que comprende los meses de enero a mayo de 1994) que la Policía Nacional Civil había comenzado a ser cuestionada por su "posible militarización" y que percibía "una sensible alza en el número de denuncias en contra de la Policía Nacional Civil, explicable quizá por el despliegue casi total en el territorio nacional, las cuales son preocupantes en tanto se han violado por parte de los mismos agentes no sólo procedimientos legales, sino también los derechos a la libertad y la integridad personal".

Mientras la Procuraduría buscaba explicarse y explicarnos las violaciones crecientes en el despliegue - necesario, por cierto - de los nuevos agentes en todo el país, los problemas a resolver dentro de este nuevo cuerpo iban en aumento, tanto en su cantidad como en el nivel de gravedad. El Secretario General de Naciones Unidas, en su informe al Consejo de Seguridad del 31 de octubre sobre ONUSAL, describía así la situación: "Los problemas de disciplina cada vez mayores, unidos a las continuas deficiencias en el entrenamiento y a los defectos en el marco jurídico que rige las operaciones de la Policía Nacional Civil, subrayan nuevamente la necesidad de una aplicación más expedita y eficaz de las recomendaciones de la ONUSAL a fin de que se corrijan las irregularidades observadas en la Policía Nacional Civil y en la Academia de Seguridad Pública... y de ese modo no se siga perdiendo la confianza del público en la nueva fuerza". Tras eso, advertía lo siguiente: "Hasta que se resuelvan estos problemas, la Policía Nacional Civil seguirá siendo una entidad frágil e incapaz de hacer cumplir la ley eficazmente. Una de las posibles consecuen- 
cias sería la tendencia a imponer el orden mediante prácticas ajenas al marco jurídico".

Muy lejos del juicio emitido por la máxima autoridad de Naciones Unidas, la Procuraduría sólo alcanzaba a plantear en el segundo número de su boletín mensual - denominado Conciencia y publicado en octubre de 1994- que, ante la compleja situación de violencia en la que vive la población, la Policía Nacional Civil debía ser "un muy eficaz instrumento para restituir a la población el derecho a la seguridad y para combatir el crimen y el delito en general, todo ello dentro de una conducta de respeto a la legalidad y a los derechos humanos". La Procuraduría formula esta aspiración después de señalar, en el mismo boletín, que el nuevo cuerpo policial no había alcanzado a concretar ni siquiera el 6 por ciento de las 3,780 órdenes de captura que recibió del Organo Judicial entre enero de 1993 y agosto de 1994. Sin duda, esa situación ponía en tela de juicio la posibilidad de concretar la primera parte del deseo antes citado: ser eficaz "para restituir a la población el derecho a la seguridad y para combatir el crimen y el delito en general". De igual manera, la segunda parte de dicha aspiración - cumplir sus funciones "dentro de una conducta de respeto a la legalidad y a los derechos humanos"- no parecía muy próxima a la realidad, dado que la misma Procuraduría reconoce que "algunos hechos recientes... siembran dudas respecto a la dirección en que se está desarrollando la Policía Nacional Civil" así como "un creciente involucramiento de sus agentes en conductas violatorias de los derechos humanos".

Más que una descripción de la situación en que se encuentra la Policía Nacional Civil y lo que debería ser, lo cual no es malo que se haga, la Procuraduría debe actuar de manera más clara, oportuna, creativa, enérgica y eficaz para evitar que se siga transitando en la dirección incorrecta y que después sea más difícil retornar al rumbo correcto. Sin embargo, en ningún momento, la Procuraduría para la Defensa de los Derechos Humanos mencionó y mucho menos criticó en el análisis citado que las antiguas unidades de la Policía Nacional hubiesen sido integradas en el nuevo euerpo policial sin un proceso previo de

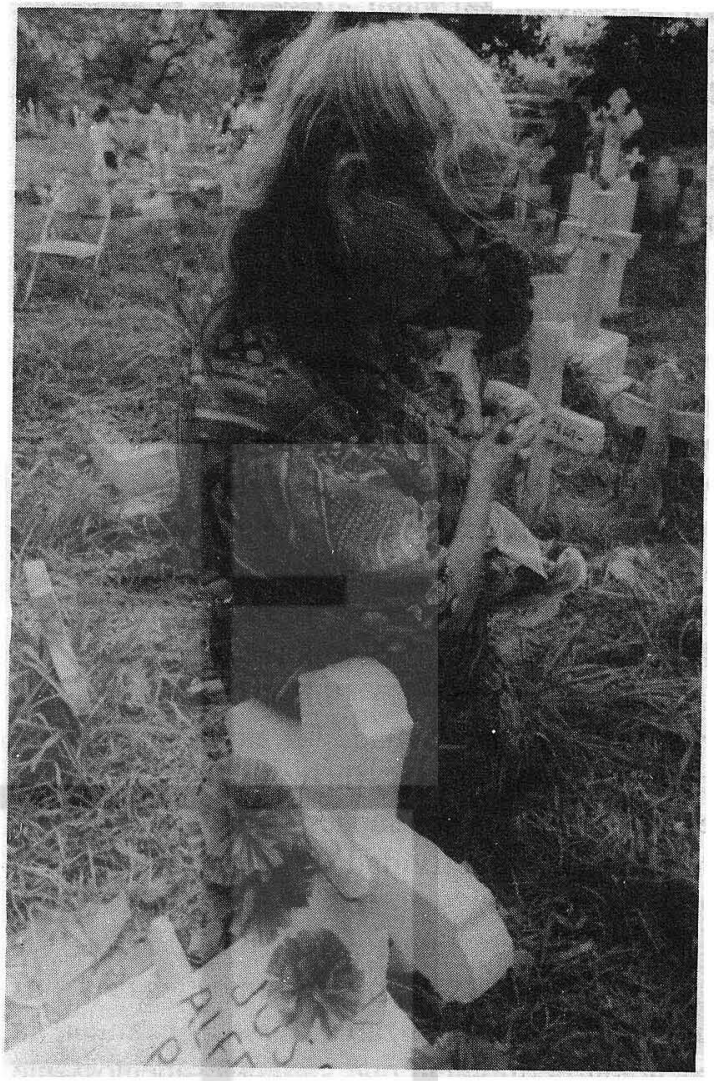

evaluación y depuración. Para combatir la falta de una sanción justa a todo nivel, no sólo en lo referente a las irregularidades de la Policía Nacional Civil, lo único que la Procuraduría para la Defensa de los Derechos Humanos alcanzó a percibir en ese entonces y eso como una insinuación - pues hasta el momento no se conocen acciones concretas - fue que un "enfoque interinstitucional con participación de la Corte Suprema [de Justicia], la Policía Nacional Civil, la Fiscalía [General de la República] y la Procuraduría parece ser el camino más adecuado para establecer de inmediato políticas y acciones específicas para reducir el alarmante índice de impunidad".

Si esto no se lleva a cabo de inmediato, tal como se dice, no sirve de mucho. A estas alturas, no conocemos qué pasos concretos se han dado en este sentido. Tampoco es muy útil que se mencione - como un "uso responsable de la facultad que la ley le confiere"- que el Procurador haya aprobado la nominación del inspector general de 
la Policía Nacional Civil a partir de la recomendación que le hizo la Comisión Nacional para la Consolidación de la Paz (COPAZ), por ser ésta según se dice- reflejo del consenso político nacional, cuando las organizaciones no gubernamentales de derechos humanos le habían manifestado, días antes, su desacuerdo con tal nombramiento.

En la edición siguiente de su publicación mensual, en la sección dedicada al análisis de la situación, la Procuraduría ya sólo menciona a la Policía Nacional Civil junto a la Policía Nacional y Municipal, adjudicando a las tres instituciones responsabilidad en el 34.29 por ciento del total de las denuncias recibidas o de los casos asumidos de oficio. Después sólo la vuelve a citar en un apartado dedicado a la Policía Municipal, "el Procurador ya ha llamado la atención sobre la Policía Nacional Civil y la necesidad de que se desarrolle bajo los dos supuestos que inspiraron su creación: a) efectividad en el combate a la delincuencia y en la protección a la ciudadanía, y b) conducta institucional e individual de respeto a la ley y a las normas de protección de los derechos humanos". Para finalizar su escaso examen, la Procuraduría dijo algo que ya todos sabemos: que el nuevo cuerpo policial "aún está lejos de estos objetivos". Sin embargo, intenta arreglar la situación afirmando que tenía "en su haber el hecho de ser una policía en formación y con vocación de cumplir su mandato constitucional".

Tanta superficialidad para tratar los elementos y las situaciones que conspiran y actúan, desde dentro y desde fuera, contra la buena marcha de la Policía Nacional Civil no es extraña en la Procuraduría. De la misma manera se ha desenvuelto en coyunturas y ante acontecimientos importantes que, desde la firma de la paz y el nombramiento del actual procurador, han tenido lugar en el país. Esta falta de profundidad en las actuaciones de la Procuraduría ha incidido de manera preocupante en la falta de garantía que existe actualmente en lo relativo al respeto de nuestros derechos y libertades fundamentales.

Cabe recordar que, el 27 de julio, un grupo de instituciones que trabajamos en esta materia como parte de la sociedad civil publicamos un des- plegado sobre la actividad de la Procuraduría para la Defensa de los Derechos Humanos. Era un intento para hacer un llamado a la reflexión desde el lado de aquellos y aquellas que durante años y con mucho sacrificio, dedicamos esfuerzos sinceros - sin privilegios ni posibilidad de mejorías económicas- para conseguir la vigencia de los derechos humanos. Nuestras recomendaciones cayeron en el vacío, pues hasta ahora no se han adoptado las medidas necesarias para superar las deficiencias y brindar a la población una institución estatal eficaz y eficiente para su servicio. De igual forma, como IDHUCA hemos hecho una serie de planteamientos para que la Procuraduría para la Defensa de los Derechos Humanos mejore su desempeño (ver $E C A, 1994,552$, pp. 1121 y 1122).

Sin embargo, hasta el momento, se desconoce el diagnóstico de la Procuraduría sobre la situación de los derechos humanos y, lamentablemente, las prioridades de trabajo establecidas por la institución — publicadas el 8 de septiembre- no responden a las exigencias y urgencias del momento. Desde nuestra práctica cotidiana, nos surgen dudas en torno al impacto que estas medidas puedan tener, pues después de su publicación no se observan cambios de fondo en el funcionamiento de la Procuraduría ni la población ha cambiado sustancialmente su percepción sobre ella. Al contrario, nuestras experiencias en la relación con la Procuraduría para la Defensa de los Derechos Humanos durante estos últimos meses han seguido siendo poco alentadoras.

Muchas de las acciones propuestas no pasan de la superficie. No enfrentan los verdaderos y grandes retos de un proceso frágil, el cual - como lo señaló ONUSAL en su onceavo informe sobre la situación de los derechos humanos en El Salvador- "será siempre precario hasta que las instituciones del Estado cuenten con la eficacia para prevenir y sancionar las violaciones a los derechos humanos", cuya "principal fuente" sigue siendo la impunidad. En este contexto, nos encontramos con la continuada ausencia de la Procuraduría o bien con intervenciones poco claras $\mathrm{y}$, además fuera de lugar. 
Pero no sólo existen la Policía Nacional Civil y la Procuraduría para la Defensa de los Derechos Humanos. Durante los últimos días de julio, fuimos muchos los que observamos con entusiasmo la elección de los magistrados de la actual Corte Suprema de Justicia. Más de cuatro meses después de esta elección, conviene analizar el estado del sistema judicial y de la administración de justicia.

Según el Secretario General de Naciones Unidas, mientras "no se lleva a cabo la reforma judicial, el marco institucional que garantiza el imperio de la ley y el respeto de los derechos humanos seguirá siendo poco sólido" (informe al Consejo de Seguridad de octubre de 1994). Partiendo de lo anterior y sobre todo de la perspectiva de la división de derechos humanos' de ONUSAL (expuesta en el doceavo informe), revisemos en qué estado se encuentran las principales medidas que debían adoptarse para garantizar dicha transformación judicial.

Sin duda, por el crítico cuadro que existía antes de la tardía elección de los nuevos magistrados que ahora integran la Corte Suprema de Justicia, es válido compartir ciertas apreciaciones positivas que se hacen en dicho informe, sin caer en excesos. Es correcto esperar mucho de quienes ahora ocupan una magistratura en el máximo tribunal del país, pero no por haber cambiado a las personas debemos dar por finalizada la tarea, otorgándole el visto bueno a uno de los aspectos que más ha incidido en la crisis del Estado salvadoreño.

Es un buen inicio que, tal como señala el documento, los nuevos servidores públicos "expresaron su intención de proceder a la revisión y restructuración del aparato administrativo y a la depuración del Organo Judicial, como pasos previos a la profundización de la reforma judicial, que requiere, como los propios magistrados han señalado, la realización de acciones en muy diversos órdenes". Pero no es suficiente. Si a lo anterior se agregan algunas iniciativas en relación a la dirección y el trabajo del Instituto de Medicina Legal, así como la forma cómo se ha considerado la información proporcionada por ONUSAL y por el Consejo Nacional de la Judicatura sobre los funcionarios judiciales "que, de acuerdo a quejas verificadas, han incurrido en inconducta funcional", debe afirmarse que eso también es positivo. Sobre todo cuando, tras la publicación del informe de ONUSAL y las declaraciones directas del jefe de la misión en torno al tema, algunos de esos funcionarios han sido fuertemente sancionados.

Se deben mencionar las actividades realizadas por ONUSAL para fortalecer la administración de justicia. Por un lado, se habla de "cursos a nivel nacional para contribuir a la especialización de los magistrados, los jueces de primera instancia y los jueces de paz, en la aplicación de las normas internacionales de derechos humanos que hacen parte de la legislación salvadoreña, con la finalidad de que las apliquen en sus razonamientos y fallos de manera preferencial y concordada con las normas de origen interno". A ello se suma una encuesta anónima para conocer la opinión de los jueces de paz y de primera instancia, así como la de los fiscales.

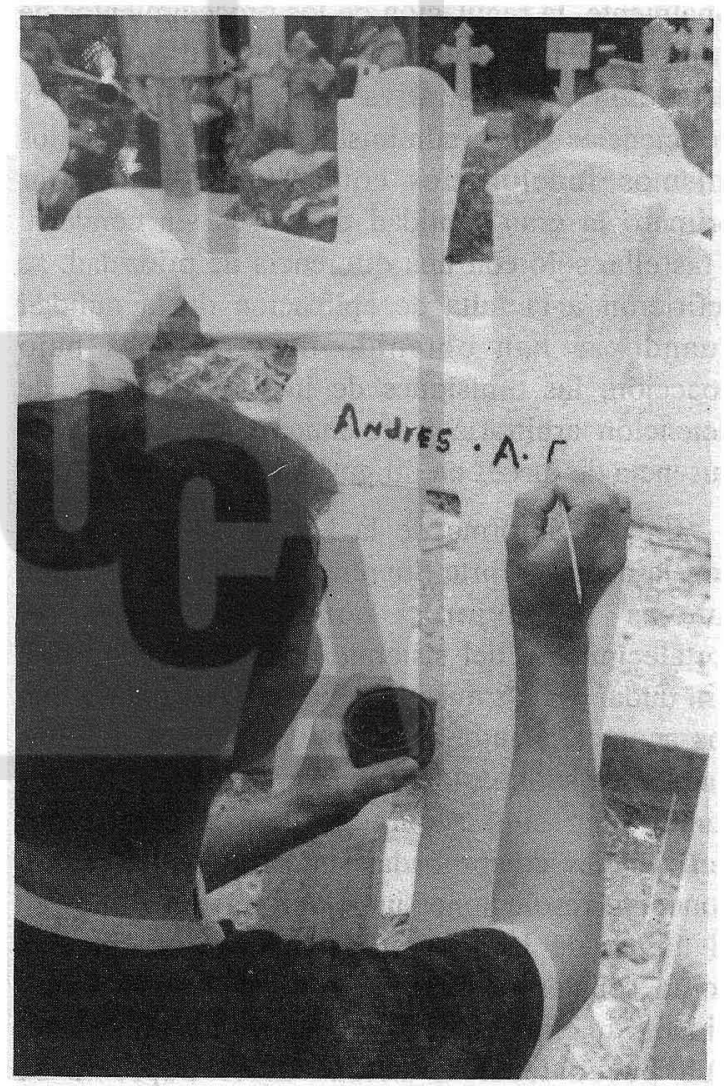


Tanto jueces como fiscales, en la práctica, coinciden. Según el 71 por ciento de los jueces de primera instancia y el 91.3 por ciento de los de paz, la vigencia de los derechos humanos es "insuficiente". El principal problema que afecta su independencia se encuentra en las presiones jerárquicas (29.6 por ciento de los jueces de paz y 34 por ciento de los de primera instancia). La mayor dificultad en su relación funcional se da con la Procuraduría General de la República (27.7 por ciento de los de primera instancia y 30.7 por ciento de los de paz).

Sobre las reformas a la ley, los funcionarios mencionaron, en orden de urgencia, las siguientes: la ratificación por parte de la actual asamblea legislativa de las reformas constitucionales aprobadas por la asamblea anterior, la aprobación de los códigos Penal y Procesal Penal, así como de la ley penitenciaria, la derogación de la confesión extrajudicial, la elaboración y aprobación de un proyecto de ley sobre el habeas corpus $\mathrm{y}$, finalmente, la regulación de los procedimientos de captura y la reducción de los plazos de la detención administrativa. Entre las principales deficiencias de la administración de justicia, los mismos funcionarios coincidieron en señalar primero la gran cantidad de presos sin condena. Tras ella, sólo con una diferencia de prioridad, se refirieron a la falta de aplicación de la nulidad cuando se han obtenido declaraciones bajo coacción, las omisiones de justicia en casos de detención arbitraria y de muerte, así como a la ausencia de jueces en diligencias importantes.

En este informe de la Misión se apunta que con la actual "Corte Suprema de Justicia se abren nuevas y mejores condiciones para el fortalecimiento del sistema judicial salvadoreño". Sin duda, esa afirmación debe ser confrontada con los acontecimientos posteriores. Algunos de ellos ya pueden ser considerados por el análisis. Ciertos jueces han sido separados de sus cargos por deficiencias comprobadas; mientras tanto, se han conocido resoluciones judiciales que, al menos en el ánimo de la opinión publica, no se aprecian como señales de mejoría para superar la impunidad. Sin embargo, nos preocupan las prioridades que pueda tener la actual Corte Suprema de
Justicia, puesto que aún no da respuesta a los recursos de inconstitucionalidad presentados por diversas organizaciones de la sociedad civil ante la ordenanza municipal que prohíbe las manifestaciones de la población en las calles de San Salvador en los días laborables.

Pero lo más inquietante es que aún no se advierte que exista voluntad política por parte de quienes deben aprobar las reformas legislativas, constitucionales o no, para enfrentar los graves problemas que afectan a la población que busca justicia. Como opina ONUSAL, el "inexplicable retraso" en su aprobación "es uno de los principales obstáculos en la actualidad para el mejoramiento de la administración de justicia y de los medios de protección de los derechos humanos en el país".

Finalmente, tras observar el panorama salvadoreño con algunas tímidas luces, pero amenazado por peligrosas sombras, ¿por qué no podemos ni debemos perder la esperanza? Pues porque ésta estuvo presente en el sueño de nuestros mártires, conocidos y anónimos, quienes nos siguen indicando el camino de la verdad y la justicia como cimiento para la instauración de una paz y una reconciliación sólidas. Porque fue la esperanza de alcanzar una sociedad diferente la que los movió a la entrega personal y al sacrificio de sus vidas, para finalizar la guerra y diseñar nuevas instituciones democráticas cuya eficacia real aún está pendiente, pues ha sido postergada por la acción consciente o la omisión irresponsable de aquellos que han tenido en sus manos el cumplimiento de los acuerdos de paz y no lo han hecho, dejando de lado las aspiraciones de una población que ansía la tranquilidad que brinda vivir en condiciones dignas a todo nivel.

No podemos arrojarnos en los brazos de la desesperanza, pues existen otros factores que nos animan a seguir trabajando. Entre ellos, el contar con referentes concretos que nos marcan el rumbo: el cumplimiento de los acuerdos de paz y las recomendaciones de la Comisión de la Verdad, de ONUSAL y del experto independiente en derechos humanos, Pedro Nikken. A ello debe agregarse, como otro factor que alienta a continuar en el es- 
fuerzo, la existencia de nuevas o renovadas instituciones que - independientemente de su falta de funcionamiento adecuado en este momentopueden ser asumidas por la población como suyas en el futuro inmediato para defender y promover sus derechos. Dichas instituciones eran impensables en el pasado reciente y ahora, por encima de todo, existen y es nuestro deber hacer que trabajen en forma correcta.

En esta hora, en El Salvador nos encontramos transitando por un momento decisivo de la historia nacional. Nadie puede decir que nuestras y nuestros mártires murieron en vano porque en el país todavía están presentes la injusticia social, la violencia, la impunidad, la inseguridad y la corrupción. Sin duda, ahora más que nunca, la realidad nos está exigiendo que participemos, utilizando esas instituciones y que las hagamos funcionar, de una vez por todas, para que contemos con los mecanismos adecuados que nos per- mitan resolver los conflictos sin apelar a la violencia.

Nos encontramos en un momento en el que tanto el trabajo de la Procuraduría como el de la Corte y el de la Policía Nacional Civil, reclaman una seria reflexión. Estamos ante la posibilidad de que en dichas instituciones se instalen y consoliden vicios del pasado; pero, también, nos encontramos ante el reto de lograr que cumplan su misión y se realicen las aspiraciones de justicia y respeto a nuestros derechos y libertades. Ya no estamos en guerra y contamos con nuevas instituciones. Todo esto es bueno, pero no basta para cantar victoria. Para ello, también debe existir una población consciente y activa que participe, vigilando el comportamiento de los funcionarios y la correcta aplicación de la ley. Ese papel nos corresponde y, esperanzados, lo debemos empezar a jugar.

\section{IDHUCA}

